\title{
RESISTÊNCIA E UTOPIA EM VIDAS SECAS, DE GRACILIANO RAMOS
}

\section{Renildo Ribeiro*}

Resumo: Neste artigo, além de salientar o fazer artístico de Graciliano Ramos, que, tendo como ponto de partida a realidade sócio-cultural do Nordeste brasileiro da década de 30 , consegue retratá-la através de sofisticada elaboração narrativa em suas obras, busco, ancorado em estudiosos da utopia como Ernst Bloch, Karl Mannheim, Vita Fortunati, Beatriz Berrini, Teixeira Coelho, analisar as manifestações e configurações da utopia presentes em Vidas Secas.

Palavras chave: Resistência. Utopia. Graciliano Ramos. Vidas Secas.

No fundo de cada utopia não há somente um sonho, há também um protesto.

Oswald de Andrade

No presente artigo, pretendo, além de destacar elementos indicadores de reconfigurações da dimensão utópica em Vidas Secas, salientar a genialidade e a grandiosidade estilística de Mestre Graça, ao conseguir, a partir de uma realidade singular, o Nordeste brasileiro da década de 30 , contemplar mais amplamente a realidade sóciocultural de um país em desenvolvimento.

O diálogo entre literatura e utopia, crucial para a presente discussão, não está centrado nas utopias tradicionais como $A$ República, de Platão, e Utopia, de Thomas More. Essa possibilidade de diálogo entre os campos discursivos da literatura e da utopia, com visão menos direcionada às questões formais de gênero, foi contemplada por Ernst Bloch, cuja obra central, The principle of hope (1995), apresenta um compêndio das mais variadas expressões culturais de configurações utópicas, observando desde os desejos consumistas dos cidadãos comuns até fenômenos de maior sofisticação, como é o caso das manifestações artísticas e literárias.

Aluno do mestrado em Literatura Brasileira da Universidade Federal de Alagoas. 
Segundo os dicionários, utopia é a denominação dada à comunidade ideal onde se vive em harmonia e em perfeitas condições de vida. O termo utopia, etimologicamente falando, é de origem grega e soma a partícula où, que significa não, com topos, que quer dizer lugar. Portanto, utopia é o não-lugar, o lugar nenhum. A criação da palavra utopia deve-se ao texto de Thomas More, obra que designava um espaço insular, um novo espaço, onde o regime de governo era uma república ideal. Cabe salientar que o termo perdeu seu significado específico e original, de designação de uma obra artística, passando a ter uso e concepções comuns. Contudo, uma constante que perpassa todos os conceitos de utopia, mesmo que disfarçadamente, é a força transformadora, pois, ao sugerir uma comunidade ideal, direta ou indiretamente, está se fazendo uma crítica à realidade existente. Como bem afirmou Oswald de Andrade (1970), utopia é um fenômeno social que faz marchar para a frente a própria sociedade.

O termo utopia (não-lugar), por fazer alusão a lugares idealizados e perfeitos, aparenta estar relacionado com um outro tempo e uma outra dimensão. Segundo Fortunati (2001), utopia é o lugar que nos revela a origem e a construção de uma comunidade feliz.

Utopia is, in fact, the place which gives rise to the happy community and, above all, the term is an oxymoron, in the sense that its meaning is completely played out on the opposition between real and ideal, between being and not being (FORTUNATI, 2001, p.10).

Pode-se dizer que a intenção do criador e idealizador da utopia é cancelar tudo que veio antes e recomeçar uma nova história, em um novo mundo. Pensar em utopia é pensar na capacidade que a humanidade possui de se opor a situações desagradáveis e lutar para a reorganização da ordem existente. A utopia é um projetar, um lançar para adiante, um sonhar acordado, é um projeto idealmente perfeito e que poderá ser concretizado num futuro, configurando-se, desse modo, como um projeto de realização.

Segundo Karl Mannheim (1986), um estado de espírito é utópico quando está em incongruência com o estado de realidade dentro do qual ocorre. Essa incongruência evidencia-se pelo fato de o 
estado de espírito utópico, na experiência, no pensamento e na prática, orientar-se para o que não existe na situação real.

Nas palavras de Beatriz Berrini:

A insatisfação com o presente arrasta o homem a se refugiar nas lembranças do passado, que ele embeleza e aprimora: lá para trás ficou um tempo e mundo feliz, irrecuperável. Ou então, leva-o a criar um espaço imaginário, diferente da realidade em que está mergulhada e por isso poderá satisfazê-lo: lá eu seria ou serei feliz... O início confundir-se-ia com o fim (1997, p 49).

Ernst Bloch chama de sonhos diurnos a consciência de algo futuro; segundo ele, esses sonhos são os elementos desencadeadores da produtividade sonhadora responsável pelo surgimento das utopias (apud MÜNSTER, 1993).

No entanto, nem todo estado de espírito que se encontra em incongruência com o real e o transcende deve ser considerado utópico. Para Mannheim, são utópicas as orientações que, transcendendo a realidade, tendem a ser transformadas em conduta, a abalar, seja parcial ou totalmente, a ordem das coisas que prevalece no momento. Ele limita o termo utopia ao tipo de orientação que transcende a realidade e, ao mesmo tempo, rompe com as amarras da ordem existente.

Mannheim também estabelece distinções entre os estados de espírito utópico e ideológico. Uma pessoa, segundo ele, pode se orientar para objetos que sejam estranhos à realidade e que transcendam a existência do real, o que é realizável conservando-se a ordem das coisas existentes. Nessa situação, temos um estado de espírito ideológico, só passando a ser utópico quando a orientação tender a pôr fim à ordem existente, caracterizando-se, desse modo, como idéias que oferecem possibilidades revolucionárias.

Para Mannheim, as ideologias "são idéias situacionalmente transcendentes que jamais conseguem, de facto, a realização de seus conteúdos pretendidos" (1986, p. 218). As utopias "também transcendem a situação social, pois também orientam a conduta para elementos que a situação, tanto quanto se apresente em dada época, 
não contém" (1986, p. 219). Porém, essas utopias não são ideologias, na medida e no ponto em que conseguem, através da contra-atividade, transformar a realidade existente em outra realidade, mas de acordo com suas próprias concepções.

Um dos aspectos fundamentais observados em Vidas Secas é a resistência do homem sertanejo diante das adversidades que o cercam. Fabiano e sua família são seres possuidores de uma força impulsionadora que lhes permite resistir às adversidades geográficas e sociais que enfrentam e marchar em busca da construção de um futuro projetado e direcionado a uma melhoria das condições de vida humana. Essa força impulsionadora é produto do que E. Bloch denominou de sonhos diurnos, que estão atrelados a um sonhar para a frente, a um projetar-se no futuro, contrariamente aos sonhos noturnos, que, segundo a leitura de Bloch da obra de Freud, estão atrelados ao passado.

O elemento utópico está sujeito a mudanças de conteúdo e forma. Essa constante mudança do elemento utópico, segundo Teixeira Coelho (1980), é produto da força que leva homens e mulheres a se oporem às circunstâncias desfavoráveis. Essa força, que, para Bloch, nasce dos sonhos diurnos, Coelho denomina esperança, força do sonho, porém só a imaginação, não a comum, mas a utópica, adequa-se a esse propósito, por ser capaz de prolongar o real em direção a um futuro passível de ser melhorado.

Cabe ressaltar que a imaginação utópica não é delirante ou fantástica e prima pela concretude, além de ser uma fonte inesgotável. Sua não-continuidade aniquilaria a humanidade, o que termina por fazer do pensamento utópico um traço humano necessário à sobrevivência. Fabiano e família, graças à imaginação utópica assim concebida, conseguem transformar os sofrimentos, as dores e as angústias do cotidiano em forças de resistência. Forças estas que os alimentam e permitem-lhes prosseguir a caminhada, acreditando na possibilidade de um bom lugar.

$\mathrm{Na}$ tentativa de registrar os elementos utópicos em Vidas Secas, suas configurações e representações, apontarei sua presença através da observação de traços estilísticos e sociológicos presentes na obra e que, na minha concepção, servem de suporte para os traços utópicos. A presença de tais elementos nessa obra também será 
interpretada como um estímulo produzido através da arte, que pode agir no sentido de suscitar uma reflexão, sob o viés da consciência utópica, sobre a realidade sócio-político-cultural nela recriada.

O romance de 30, dentre eles Vidas Secas, colocou-nos em contato com um Brasil pouco conhecido, multifacetado, apresentado em sua diversidade regional e cultural, mas com problemas comuns em quase todas as regiões: a miséria, a ignorância, as opressões nas relações de trabalho. Configurou-se, assim, o romance desse período, como o movimento literário mais representativamente realista da literatura brasileira.

A crise da sociedade colonial brasileira apresentava-se, no Nordeste, com maior intensidade, o que fez com que os movimentos de renovação, que começaram a esboçar-se por todo o país, entrassem em confronto, no Brasil, com barreiras mais firmes e obstáculos quase intransponíveis.

O romance desse período deve ser configurado como depuração da realidade, e não como sua transcrição. A problemática abordada em Vidas Secas não deve ser vista e interpretada como sobreposição de quadros representativos de uma dada realidade regional. Temos sim a captação de uma nova realidade como consciência de um problema. É a consciência da decadência do sistema feudal, da falta de apoio por parte dos proprietários e a ganância pelo lucro, que ganha estrutura, densidade e apresenta-se como elemento desencadeador da problemática central da obra.

O espaço do romance é marcado pela aridez e pela falta de condições para o desenvolvimento e a sobrevivência do ser humano. Contudo, com as mínimas condições favoráveis, a realidade transforma-se e, no mundo inóspito, após as chuvas, "a fazenda renasceria e ele [Fabiano] seria o vaqueiro, para bem dizer dono daquele mundo" (VS, p.17). Os personagens, assim como o espaço romanesco, diante da possibilidade de melhoria, por menor que seja, encenam a renovação das forças voltadas à busca da afirmação da vida. A falta, que perpassa toda a obra, a realidade degradada, os seres abandonados e carentes, tudo faz com que o romance se estruture como uma narrativa de busca. Temos, na obra, a busca dos juazeiros, que ao longe metaforizam o princípio da esperança, com o ideal de que um futuro melhor que espera os que se aventuram; a busca de 
água para a sobrevivência; a busca de um emprego; e a busca de uma identidade por Fabiano. Temos também os desejos de Sinha Vitória por uma saia de ramagens e por uma cama de couro'; o desejo do menino mais novo, que busca imitar o pai e subordina sua felicidade à condição de possuir um periquito; a busca de compreensão do mundo por parte do menino mais velho, metaforizada através da instigante e significativa reflexão sobre o sentido do vocábulo inferno. E, por fim, temos a cachorra Baleia, que busca um preá, num dos momentos mais delicados vividos pelo grupo, e procura suprimir a realidade má e as agruras que a cercam com pensamentos revolucionários e sonhando com um mundo cheio de preás, numa verdadeira cocanha canina ${ }^{2}$.

As ações de Vidas Secas acontecem intercaladas entre duas grandes secas, período relativamente curto para a grandiosidade e complexidade dos problemas expostos na obra. Logo nas primeiras páginas do romance, encontramos o seguinte quadro:

Sinha Vitória com o filho mais novo escanchado no quarto e o baú de folha na cabeça, Fabiano sombrio, cambaio, o aió à tiracolo, a cuia pendurada numa correia presa ao cinturão, a espingarda de pederneira no ombro. O menino mais velho e a cachorra Baleia iam atrás (VS, p. 9).

No último capítulo, a cena acima citada repete-se quase exatamente da mesma maneira, porém, agora, o quadro humano sofre algumas modificações:

Desceram a ladeira, atravessaram o rio seco, tomaram rumo para o Sul. [...] os meninos à frente, conduzindo trouxas de roupa, Sinha Vitória com o baú de folhas pintada e a cabaça de água, Fabiano atrás de facão de

1 Sobre os desejos de Sinha Vitória, ver MAGAlHÃES, Belmira. Vidas Secas: os desejos de Sinha Vitória, texto em que a autora faz uma leitura marxista do romance e ressalta o importante papel da esposa de Fabiano, não só na vida daquelas gentes, como também na construção narrativa da obra.

2 Sobre Cocanha, ver importantes estudos de FRANCO JUNIOR, Hilário. Cocanha: a história de um país imaginário. São Paulo: Companhia das Letras, 1998 e Cocanha: as várias faces de uma utopia. Cotia: Ateliê Editorial, 1998. 
rasto e faca de ponta, a cuia pendurada por uma correia amarrada ao cinturão, o aió a tiracolo, a espingarda de pederneira no ombro, o saco da malotagem no outro (VS, p.124).

Apesar de descrever quadros bastantes típicos dessa determinada região, Graciliano rompe com o reducionismo pretendido pelo realismo oitocentista, não havendo nada de comum entre seu regionalismo e aquele que, segundo Carlos Nelson Coutinho (1979), foi uma das representações brasileiras do naturalismo sóciológico.

O regional de Graciliano focaliza quadros cotidianos da realidade brasileira, conseguindo, conseqüentemente, atingir $o$ universal, por meio do enfoque de elementos extremamente singulares. Ou seja, Graciliano, através do registro metonímico do Nordeste do Brasil, consegue, em Vidas Secas, abordar questões referentes ao latifúndio e ao desenvolvimento social do homem não só em nível nacional, mas, sobretudo em nível universal. O universal a que me refiro diz respeito às atitudes e aos comportamentos dos personagens da obra que se encontram em constante sintonia com questões do gênero humano, tanto nacional, quanto globalmente. E, como afirma Coutinho (1979), essa universalidade não é abstrata e sim concreta, pois vive e se alimenta da singularidade, da temporalidade social e histórica. Graças a este procedimento, a elevação do singular ao universal, os temas brasileiros deixaram de ser exóticos, e qualquer leitor, de qualquer parte do mundo, pode identificar-se com os homens e mulheres nordestinos descritos por Graciliano Ramos na obra aqui analisada.

As personagens de Vidas Secas são seres oprimidos pela consciência de isolamento, seres fragmentados que, apesar de sua solidão interior, lutam pela afirmação da individualidade.

Graças a uma estrutura agrária retrógrada e improdutiva que oferece obstáculos frente ao avanço das forças produtivas, há a migração dos camponeses. Lembremos que Fabiano é forçado, pelas circunstâncias, a contrair dívidas com seu patrão, pois

Se pudesse economizar durante alguns meses, levantaria a cabeça. Forjara planos. Tolice, quem é do chão não se trepa. Consumido os legumes, roída as espigas de milho, recorria a gaveta do amo, cedia por preço baixo os 
produtos das sortes. [...] Transigindo com outro, não seria roubado tão descaradamente. Mas receava ser expulso da fazenda. E rendia-se. Aceitava o cobre e ouvia conselhos (VS, p.9).

Pode-se claramente afirmar que Graciliano Ramos relacionou, em uma estrutura organicamente coerente, os vários problemas que generalizam e tipificam o universo agrário brasileiro, representando-os em situações e destinos humanos concretos, tais como: a exploração social, a solidão das personagens e a consciência contraditória do camponês brasileiro. No mundo de Vidas Secas, há uma estagnação social que condena os seres a uma vida medíocre constituindo, desse modo, parte de um mundo mesquinho, sem perspectivas e bastante separado da possibilidade de uma vida mais plenamente social e comunitária. Todos esses fatores são frutos de uma sociedade précapitalista. O nosso caso é específico, pois temos uma sociedade semicolonial penetrada por elementos capitalistas - elementos esses que, segundo Carlos Nelson Coutinho (1977, p. 75), ao invés de promoverem uma transformação social revolucionária, acentuaram o isolamento, a solidão, e a restrição do ser humano a um pequeno mundo de mesquinha vida privada. Desse modo, quando as transformações políticas se tornavam necessárias, elas eram feitas pelo alto, sem participação coletiva.

Fabiano, em Vidas Secas, desconhece a vida comunitária, isto é, faz parte de uma parcela isolada da sociedade desprovida dos modos e vivências do povo das cidades. No capítulo Festa, ele sentese preso, amarrado junto àquele povo. Já no campo, mesmo preso às roupas típicas de vaqueiro, "metido numa caixa, como tatu" (VS, p. 79), Fabiano saltava no lombo de um animal e voava na caatinga. Em O mundo coberto de penas, Fabiano percebe sua condição de isolamento diante do mundo: "Impossível dar cabo daquela praga. Estirou os olhos pela campina, achou-se isolado. Sozinho num mundo coberto de penas, de aves que iam comê-lo" (VS, p.120).

Em Vidas Secas, o setor em foco ainda não havia sido penetrado a fundo por elementos capitalistas, como acontece em São Bernardo. No entanto, já observamos que são bastante fortes a ganância pelo lucro e a exploração do outro. Há uma certa tendência a levar vantagem sobre os outros e, como sempre, o explorado é geralmente o ser humano menos instruído e menos privilegiado 
socialmente. Observa-se também esse ponto no capítulo Cadeia, em que Fabiano vai à feira da cidade comprar mantimentos e tem receio de ser ludibriado, pois sabia ele "que todos os caixeiros furtavam no peso e na medida" (VS, p.28) e seu Inácio "botava água em tudo" (VS, p.28) e também na redação com Sinhá Terta, que falava como gente da rua, "achava pouca a fazenda, e Fabiano se mostrava desentendido, certo de que a velha pretendia furtar-lhe os retalhos" (VS, p.75).

No que diz respeito à improdutividade do campo, o centro gerador dessa não produção é o desinteresse do proprietário que se encontra, de certa forma, ligado à lógica de exploração do sistema colonial. Graças a esse desinteresse, o proletário encontra mais uma forma de explorar o camponês.

Fabiano recebia na partilha a quarta parte dos bezerros e a terça dos cabritos. Mas como não tinha roça e apenas se limitava a semear na vazante uns punhados de feijão e milho, comia da feira, desfazia-se dos animais, não chegava a ferrar um bezerro ou assinar a orelha de um cabrito (VS, p.98).

Sobreviventes deste mundo, Fabiano e sua família são privados de qualquer possibilidade de mudança imediata. Assim como Baleia, que possuía desejos revolucionários, mas achava-se impotente contra seus agressores, Fabiano e sua família encontravam-se presos às amarras opressivas da realidade e isolados. Daí seus desejos revolucionários (matar o soldado amarelo, aderir ao cangaço), por serem projetos individuais, não passaram de idealizações. O soldado era representante do governo e "Governo é governo" (VS, p.14). Ao ser preso, o desejo de Fabiano era entrar para o cangaço e matar o soldado amarelo, melhor, "mataria os donos dele" (VS, p. 40), mas o que o segurava era a família. Em um mundo com essas configurações distópicas, uma saída disponível ao ser humano é a imaginação utópica, a força que tais seres possuem de reagir contrariamente à realidade opressora.

Graciliano ganha destaque também pelo seu estilo conciso e objetivo. O conceito de estilo aqui utilizado é definido por Carpeaux (1987, p. 243-248) como a escolha de palavras, escolha de construção, escolha de ritmos, dos próprios fatos para uma composição. O estilo 
graciliânico e a sensibilidade artística do autor conseguiram se libertar da mistura de romantismo e naturalismo que encontramos presentes, entre os contemporâneos do escritor alagoano.

Roland Morel Pinto (1987, p. 254-61), ao analisar as estruturas frásicas em Graciliano, afirma que um dos pontos mais altos da narrativa do escritor alagoano é a capacidade de concisão frasal atingida, sem, no entanto, descartar qualquer elemento essencial para a compreensão do drama narrado em suas sutilezas e intensidades. Ainda segundo esse crítico, em Vidas Secas, a linguagem é extremamente econômica e matematicamente contada, para que nada pareça supérfluo à realidade da obra. A independência dos capítulos, estruturados como contos, e, sobretudo, as sugestivas utilizações de períodos coordenados e assindéticos dão ao texto grandes possibilidades e sugestões interpretativas. Estas fendas coesivas, que em nada prejudicam a estrutura textual, sugerem aos leitores certa capacidade reflexiva diante do tema exposto, possibilitando a construção de uma consciência utópica, tendo por base os dados da realidade focada na obra de arte.

Percebe-se, desse modo, que, em Vidas Seca, há um alto grau de coerência entre forma e conteúdo. Um bom exemplo é a abundante utilização de orações assindéticas, pouca adjetivação, além da independência dos capítulos, quando retratam uma realidade em que os seres estão ligados apenas pelo meio físico, numa constante luta por sobrevivência e desejo de superação das barreiras impostas pelas estruturas de um mundo degradado, onde não há tempo nem lugar propício para o desenvolvimento de sentimentos afetivos.

O ritmo narrativo em Vidas Secas também é bastante significativo na coerência interna da obra. Vejamos estes exemplos:

Arrastaram-se para lá, devagar, Sinha Vitória com o filho mais novo escanchado no quarto e o baú de folha na cabeça, Fabiano sombrio, cambaio, o aió a tiracolo, a cuia pendurada numa correia presa ao cinturão, a espingarda de pederneira no ombro. $\mathrm{O}$ menino mais velho e a cachorra Baleia iam atrás (VS, p.9).

Observe que termos como arrastaram-se, devagar, sombrio, cambaio, iam atrás, em consonância com a construção do período longo, intercalado por vírgulas, transmitem aos leitores um certo 
cansaço, funcionando como sugestão para que esses compartilhem da luta dos personagens pela sobrevivência.

Já neste outro fragmento, localizado no mesmo capítulo, observamos o fenômeno contrário ao que acabamos de destacar. Agora, as ações são narradas logo após a captura de um preá pela cachorra Baleia, "caça que adiaria a morte do grupo" (VS, p. 14) ou até mesmo significaria a salvação deste. Observamos que todas as ações da cena são dispostas no sentido de cooperação e sustentação de um ideal, pois não esqueçamos que "Fabiano queria viver" (VS, p. 14):

Chegou. Pôs a cuia no chão, escorou-a com pedras, matou a sede da família. Em seguida acocorou-se, mexeu o aió, tirou o fuzil, acendeu as raízes de macambira, soprou-as inchando as bochechas cavadas. Uma labareda tremeu, elevou-se, tingiu-lhe o rosto queimado, a barba ruiva, os olhos azuis. Minutos depois o preá torcia-se e chiava no espeto de alecrim (VS, p.16).

Nesse excerto, as ações verbais chegar, pôr, escorar, matar, acocorar, remexer, tirar, soprar, tremer, o elevar-se da labareda e o torcer-se do preá expressam, no contexto, certa brevidade quanto à duração, que, vale ressaltar, são em quantidade bem maior do que as ações da citação anterior. Além disso, observamos os modalizadores temporais em seguida, minutos depois, dando idéia de movimento, mobilidade, ocasionando o ressurgimentos de seres calcados em um ambiente inóspito, pois "estavam no pátio de uma fazenda sem vida"(VS, p.13), onde a ausência é dominante

O curral deserto, o chiqueiro das cabras arruinado e também deserto, a casa do vaqueiro fechada, tudo anunciava abandono. Certamente o gado se finara e os moradores tinham fugido.

Fabiano procurou em vão perceber um toque de chocalho (VS, p.13).

Apesar das condições físicas dos retirantes, que estavam cansados e famintos, a simples presença dos juazeiros, que "alargavam duas manchas verdes" (VS, p. 9), constituía motivo para que buscassem energia, não se sabe onde, e se aventurassem em busca de um melhor lugar. 
Essa mobilidade, perceptível em Vidas Secas, é algo que não encontramos isoladamente, é uma constante que perpassa toda a obra. A mobilidade a que me refiro não deve ser interpretada apenas no que diz respeito ao ritmo narrativo, mas também, como um processo que abarca desde o campo semântico do nome dos capítulos, que iniciam e findam a obra, até o nível de crescimento e conscientização que os personagens sofrem, ao longo do romance.

No que diz respeito ao título do primeiro e último capítulos de Vidas Secas, temos mais uma prova de coerência entre forma e conteúdo, pois não parece ser aleatório Graciliano iniciar o livro com o capítulo Mudança e, sugestivamente, fechá-lo com o capítulo Fuga. O que me chamou a atenção foi a carga semântica de ambos os títulos, sobre os quais outras interpretações chegaram a afirmar que apenas reforçam o caráter cíclico da obra, com o que não concordo.

Apesar da aparente proximidade significativa entre Mudança e Fuga, esta limita-se ao aspecto de mobilidade sugerido pelos termos. O termo mudança está ligado ao sentido de transposição, variação ou troca; já em relação ao termo fuga, apesar de trazer implícito o sentido de deslocamento, prevalece o sentido de retirada rápida e precipitada, que sugere um lançar-se a algum lugar, o que, em nossa perspectiva de leitura, significa um projetar-se, um jogar-se em busca de uma outra realidade, a busca de uma utopia.

Façamos um rápido e breve percurso sobre a trajetória de Fabiano e Sinha Vitória a fim de percebermos o crescimento destes ao longo da obra. No início do romance, "Fabiano desejou matá-lo [o filho]". "Tinha o coração grosso, queria responsabilizar alguém pela sua desgraça [...] o vaqueiro precisava chegar não sabia onde" (VS, p. 9). Nessa cena, é perceptível a animalidade dos personagens. Porém, nesses seres embrutecidos pela vida, encontramos também a expressão de sentimento. Ou seja, junto à parte animal, há também uma fração do humano. Apesar de desejar matar o filho por atrapalhar sua marcha, Fabiano reflete e vê que aquela criatura não é culpada pela situação na qual se encontra e, olhando o ambiente de morte que o cerca, o sertanejo se compadeceu do inocente e "teve pena" (VS, p. 9).

Outro elemento que possibilita constatar a evolução dos personagens, ao longo do texto, são os diálogos dos retirantes que, de início, são constituídos apenas por interjeições guturais e gestos. No 
final da obra, no capítulo Fuga, se tivermos observado o percurso lingüístico dos personagens, encontramos seres mais articulados e conscientes da necessidade de diálogo para a sobrevivência. Eles necessitavam de interação, precisavam conversar, não uma fala repetitiva, calcada no velho, pois simbolicamente essas personagens suprimiram essa possibilidade de simples reprodução no ato de deglutir o papagaio, ave que apenas repete sons. Interpreto o ato canibalístico dos retirantes como o primeiro passo dos personagens em busca do novo. Nessa busca, Sinha Vitória ganha destaque, pois é um ser conciliador. É ela que impulsiona a construção e a busca de mudanças. No final da obra, a senhora de Fabiano sente que "precisava falar. Se ficasse calada seria como um pé de mandacaru, secando, morrendo" (VS, p. 126).

Nessa parte do romance, ao contrário da fase inicial, na qual temos seres perdidos num espaço sem direção pré-definida, os personagens partem com um rumo certo, pois "seguiram viagem para o Sul" (VS, p. 115). Os retirantes

alcançariam uma terra desconhecida. Fabiano estava contente, e acreditava nessa terra, porque não sabia como era nem onde era. [...] E andavam para o Sul, metidos naquele sonho. Uma cidade grande, cheia de pessoas fortes. Os meninos em escolas, aprendendo coisas difíceis e necessárias (VS, p. 134).

Apesar do tom bastante irônico, nesse fragmento, observamos um certo potencial de realização dos sonhos dos retirantes. A obra aponta para uma outra realidade e para a possibilidade de os personagens vivenciá-la enquanto seres sociais, mas também adverte: "Chegariam a uma terra desconhecida e civilizada, ficariam presos nela" (VS, p. 134). Com isso, a terra promissora, a utopia projetada ao final da obra, poderá transformar-se em outra distopia (mau lugar), contudo, impulsionados pelos sonhos diurnos, pode-se dar início a uma nova luta, na construção de sonhos e projetos para a superação das estruturas estabelecidas. 
Referências

ANDRADE, Oswald. As marchas das utopias. In: Do pau-brasil à antropofagia e às utopias. Manifestos, teses de concursos e ensaios. Rio de Janeiro: Civilização Brasileira, 1970.

BERRINI, Beatriz. Utopia, utopias, visitando poemas de Gonçalves Dias e Manuel Bandeira. São Paulo: EDUC, 1997.

BLOCH, Ernst. The principle of hope. Trans. N. Plaice, S. Plaice \& P. Knight. Cambridge, Mass: MIT, 1995.

CARPEAUX, Otto Maria. Visão de Graciliano. In: Graciliano Ramos: antologia e estudos São Paulo: Ática, 1987, p. 243-248.

COELHO, Teixeira. O que é utopia. São Paulo: Brasiliense, 1980.

COUTINHO, Carlos Nelson. Graciliano Ramos. In: BRAYNER, Sônia (org.). Graciliano. Rio de Janeiro: Civilização Brasileira; Brasília: INL, 1977, p.73-123 (Coleção Fortuna Crítica v 2).

FORTUNATI, Vita. Re-tracing cammon grounds in the construction of two ambivalent concepts: nation and utopia. In: Paola Spinozzi (ed.). Utopianism/literary utopias and national cultural identities. Bologna: University of Bologna: 2001, p. 9-18.

LUKÁCS, Georg. Introdução a uma estética marxista. Trad. Carlos Nelson Coutinho e Leandro Konder. Rio de Janeiro: Civilização Brasileira, 1978.

MANNHEIM, Karl. A mentalidade utópica. In: Ideologia e utopia. Trad. Sérgio Magalães Santeiro. 4. ed. Rio de Janeiro: Guanabara, 1986.

MÜNSTER, Arno. Ernst Bloch: filosofia da praxis e utopia concreta. São Paulo: Unesp, 1993.

PINTO, Roland Morel. As estruturas frásicas. In: Graciliano Ramos: antologia e estudos São Paulo: Ática, 1987, p. 254-261.

RAMOS, Graciliano. Vidas Secas. 39. ed. Rio de Janeiro: Record, 1978. 